\title{
Across the Divide: Parents' and Teachers’ Beliefs about Learning and Teaching
}

\author{
Bruce Torff \\ School of Education, Hofstra University \\ 128 Hagedorn Hall, Hempstead, NY 11549, United States \\ Tel: 1-516-463-5803Ｅ-mail: bruce.torff@hofstra.edu
}

Received: April 1, 2015 Accepted: April 16, 2015 Published: May 13, 2015

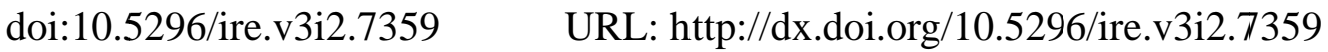

\begin{abstract}
Teachers' beliefs have been shown to exert substantial impact on educational practices, but it has remained unclear the extent to which teachers' beliefs differ from those of parents, who typically lack professional training in education. Two survey-research studlies were conducted to compare parents' and teachers' beliefs about learning and teaching. In the first study ( $n=$ 140), an eight-item, two-factor survey instrument was developed and evaluated, producing satisfactory psychometric characteristics. In the second study $(n=410)$, controlling for age, gender, ethnicity, and educational attainment, (a) parents demonstrated strong preferences for the survey's curriculum-centered items while teachers preferred the student-centered ones, (b) parents produced markedly higher ratings for curriculum-centered items than did teachers, while teachers produced higher ratings for student-centered items than did parents, and (c) parents preferred a curriculum-centered pedagogical blend while teachers favored a student-centered blend. The results support the theory that our culture's folk psychology manifests pedagogical beliefs that are remote from beliefs held by professional educators, especially concerning curriculum-centered pedagogy, potentially making communication difficult among stakeholders in schools.
\end{abstract}

Keywords: beliefs, parents, teachers, student-centered teaching, curriculum-centered teaching, home/school communication

\section{Introduction}

The gap sometimes looms large, especially when parents and teachers meet to discuss 
students' report cards. At such events it frequently happens that teachers and parents demonstrate very different views about what learning is and how teaching should proceed. Parents often seem to value "curriculum-centered" schooling long on lectures, readings, and drill-and-practice, while teachers typically favor "student-centered” pedagogy emphasizing inquiry, problem-solving, and critical thinking. In what follows I suggest a theory to account for the observed gap between parents and teachers in beliefs about learning and teaching. The theory is supported by two research studies, one to develop and evaluate a survey instrument that assesses pedagogical beliefs, and another to document incongruities between the beliefs held by parents and teachers.

\subsection{Literature Review}

It is fitting that substantial bodies of literature in psychology, education, economics, and other disciplines explores beliefs - how they are formed, what impact they have, how they change, what causes them to change. Of course, beliefs do not always align with behavior (Fang, 1996; Olafsen \& Schraw, 2006), but at minimum beliefs influence the way people perceive the world, organize their experiences, memorize information, and generate behavior (Bandura, 1997, Green \& Hood, 2013; Hofer, 2004; Perry, 1970; Richardson, 1996; Sinatra \& Kardash, 2004). Accordingly, beliefs related to educational practices are a central focus of theory and research. In addition to a substantial literature focusing on students' beliefs (e.g., Hofer, 2004; Tanriverdi, 2012), much of the work in this area examines the beliefs of classroom teachers, unsurprisingly given their role as the main providers of educational services in modern schools. Teachers' beliefs have been investigated in relation to development (Buchanan, Eccles, Flanagan, \& Midgley, 1990), classroom management (Weinstein, 1998), instructional choice (Flowerday \& Schraw, 2000), preservice field experiences (Hancock \& Gallard, 2004), locus of control (Cady \& Rearden, 2007), and particularly with regard to epistemic views (Beuhl \& Fives, 2009; Hofer, 2004; Franco et al., 2012; Kuhn \& Weinstock, 2002; Maggioni \& Parkinson, 2008; Pintrich, 2002; Schommer, 1993).

A large and growing subset of this research concerns teachers' beliefs about learning and teaching (i.e., what learning is and how teaching should proceed), often raising the distinction between curriculum-centered and student-centered pedagogies (Sampson, Enderle, \& Grooms, 2013; Varrella \& Burry-Stock, 1996). Three bodies of relevant research are reviewed below: the nature of teachers' beliefs; the development of these beliefs in as teachers accrue education and experience; and initiatives that attempt to facilitate change in teachers' beliefs.

The nature of teachers' beliefs. Snider and Roehl (2007) conducted survey research examining the pedagogical beliefs of practicing teachers in three Midwestern states. Results indicated that demographic variables such as age, teaching experience, and gender had little association with pedagogical beliefs. Significantly more teachers bellieved in teaching practices consistent with student-centered pedagogy than believed in the teacher-centered approach. However, the majority of teachers were mixed, undecided, or balanced about pedagogy.

Producing comparable results, Chen, Brown, Hattie and Millward (2012) reported that teachers whose beliefs were consistent with student-centered pedagogy were more likely to 
self-report teaching practices that comported with these beliefs, relative to teachers with more curriculum-centered beliefs. At the same time, $17 \%$ of teachers who favored student-centered pedagogy did not self-report corresponding teaching practices. Similarly, a study by Levitt (2002) indicated that most participating teachers believed that the teaching and learning of science should be student centered, but not all teachers so believed. Other research found that many teachers espoused a student-centered curriculum, although the pattern was not invariant among respondents (Olafsen \& Schraw, 2002; Torff, 2006; Warburton \& Torff, 2005).

Student teachers also demonstrated a preference for student-centered pedagogy, but with exceptions among some individuals. In a study conducted by Cheng, Chan, Tang, and Chan (2009), student teachers who had sophisticated or mixed epistemological beliefs tended to support student-centered or mixed conceptions of teaching, but cases did that did not fit the pattern also were evident.

Development of teachers' beliefs. Results as such raise the question of the development of teachers' beliefs about curriculum-centered and student-centered pedagogies. Sosu and Gray (2012) conducted a four-year longitudinal study focused on change in teachers' epistemic beliefs and instructional preferences following student teaching. Results showed significant changes in teachers' epistemic beliefs over the four-year period and these beliefs predicted teachers' instructional preferences, such that teachers' beliefs and preferences became more student-centered as a consequence of teacher education and teaching experience. But not all teachers evinced the pattern; some remained consistent in their reported beliefs and preferences.

Comparable results were reported by Olafsen, Schraw, and Vander Velt (2010), who examined epistemological and ontological beliefs using self-report surveys, written reflections, and an extended written action research project. Data were collected from for a sample of graduate students over the course of a 13-week semester. Results indicated that approximately $55 \%$ of the participants expressed consistent beliefs. The $45 \%$ of participants who did not self-report consistent beliefs typically changed from curriculum-centered to more student-centered beliefs by the end of the semester.

In a study by Torff (2005), inservice, preservice, and prospective teachers and non-teacher controls participated in cross-sectional research looking at change in teachers beliefs' over time, with the accrual of preservice and inservice education and teaching experience. Self-selection of a teaching career was associated with support for student-centered activities, while controls preferred the curriculum-centered ones. Preservice education was associated with reduced support for curriculum-centered activities. Inservice education and teaching experience were associated with reduced support for student-centered activities, but the effect was very small. Apparently teachers arrive at their first education class convinced of the merits of student-centered activities, and temper these views only slightly as they gain education and experience. They also arrive confident that curriculum-centered activities are effective, but apparently lose this confidence during preservice education and do not regain it afterward. Teacher education evidently had the effect of reducing prospective teachers' support for curriculum-centered instruction. 


\section{Ml Macrothink}

International Research in Education

ISSN 2327-5499

2015, Vol. 3, No. 2

The theme of stability and change was also evident in research conducted by Nettle (1998), who administered a survey to assess teachers' beliefs before and after studlent teaching. Some teachers remained consistent while others demonstrated belief change favoring student-centered pedagogy, and an association was found between the changes in student teachers' beliefs and the beliefs held by supervising (cooperating) teacher.

Facilitating change in teachers' beliefs. A body of research explores how teacher education can initiate changes in teachers' beliefs (e.g., Muis \& Duffy, 2013; Polat, 2010; Richardson \& Placier, 2002; Tanase \& Jian, 2010). This research is rooted in the claim that "preservice teachers hold similar initial beliefs, viewing the teacher as the authority figure passing knowledge to the students" and that to promote "constructivist practice" these beliefs "should be challenged to enable the preservice teachers to develop alternative ideas, seeing the students capable of constructing knowledge with the help of the teacher” (Tanase \& Jian, 2010; p. 1238).

A study by Muis and Duffy (2013) assessed the effectiveness of an intervention designed to foster epistemic change over the course of one semester. The intervention was based on constructivist teaching practices that incorporated teacher modeling of critical thinking of content, evaluation of multiple approaches to solving problems, and making connections to prior knowledge. Sixty-three students in two groups (intervention, $n=3 i 1$; control, $n=32$ ) completed questionnaires five times over the semester. The questionnaires measured students' epistemic beliefs, learning strategies, and levels of motivation in their statistics class. Results revealed that for students in the intervention group, epistemic beliefs shifted midway through the semester, whereas students in the control group maintained consistent beliefs throughout the semester. Intervention students' self-reported use of critical thinking and elaboration strategies also significantly increased midway through the semester, as did their levels of self-efficacy for learning statistics. In contrast, students in the control group maintained consistent levels of strategy use and self-efficacy.

Less positive results were obtained in a mixed-methods study addressing the extent to which preservice teachers' beliefs about the effectiveness of curriculum- centered and student-centered instructional materials changed after a semester-long intervention (Polat, 2010). Data were collected from 90 preservice teachers (45 experimental, 45 control) using questionnaires, semi-structured interviews, and retrospective reflection essays. Findings suggested that although change in preservice teachers' beliefs was not common, it did occur in some cases favoring the student-centered approach.

A similarly mixed picture emerged in study by Tanase and Jian (2010), who used qualitative methods to examine change in teachers' beliefs. In a study of preservice teachers enrolled in a teacher education course designed to foster belief change, pedagogical beliefs were found to be difficult to change in the course environment. Drawing on surveys and teaching observations from preservice teachers in an introductory methods course, the study showed that participants tended to remain consistent in their beliefs, but what change did occur favored student-centered pedagogy. 


\subsection{Folk Belief Theory}

The forgoing literature review reveals much about teachers' beliefs about learning and teaching. But little research has been published on individuals untrained in education. Making the case for the need for this research requires a brief synopsis of a theory discussed in detail elsewhere (Torff, 2011, 2014).

From the perspective of a theoretical framework known as cultural (or cultural-historical) psychology, exploring beliefs about learning and teaching means taking into consideration the cultural milleu in which educational practices are situated (e.g., Bruner, 1990; Cole, 1996; Sweder, 1991). From this perspective, cultures provide cognitive "tools" with which people make sense of the world and generate behavior. Some of these tools deal with human behavior and thought. The term folk psychology has been used to describe beliefs that help members of a culture make sense of how the human mind functions and what behaviors mean (Bruner, 1990; Geary, 2005; Horgan \& Woodward, 1999; Hutto, 2008). For example, swaggering after a sports triumph is considered appropriately celebratory in America, but evidence of mental illness in Japan. From this theoretical viewpoint, people in a culture conceptualize what learning is (and how teaching should proceed) with the help of folk beliefs about how the mind works. These folk beliefs provide an intuitive basis by which individuals untrained in education make sense of educational issues and form opinions about effective teaching - or actually teach, if pressed to do so.

Folk beliefs about learning and teaching. If the shared beliefs in a culture are posited to organize how people think and act, detailed investigations of the culture's beliefs are warranted (Bruner, 1990). In our culture, what are the basic tenets of the folk beliefs regarding learning and teaching? According to "folk belief theory" (Torff, 2011, 2013, in press), these beliefs hold that teaching occurs when knowledge is transmitted to learners from teachers, texts, and other media, and learning occurs when students are sufficiently intelligent and attentive to either commit knowledge to memory (e.g., memorizing the multiplication table) or develop needed skills (e.g., solving long-division problems). On this view, efficient means to transmit knowledge (e.g., lecture, readings) are valued - as is drill-and-practice, since effective schooling is seen as requiring a great deal of "nose to the grindstone" effort for which careful teacher supervision is necessary. Student-centered activities are not eschewed; people see the value in figuring things out and learning by doing. But uses for student-centered activities are few, while curriculum-centered activities are needed every day. In general, our culture's folk psychology takes a decisively curriculum-centered tack, with a slight nod to student centering.

Folk beliefs as such can be resistant to change, but sometimes belief change does occur. Beliefs in a vast array of domains have shown a tendency to hold fast over time, unchanged as development unfolds and unyielding despite intensive efforts to change them (e.g., diSessa, 1996; Gardner, 1991, 2006). Beliefs about learning and teaching are no exception (for a review see Tippett, 2010; see also Nissani \& Hoefler-Nissani, 1992; Richardson \& Placier, 2002; Sinatra, 2004). But change does happen, if sporadically, as individuals participate in preservice and inservice education and gain teaching experience - the enculturating elements 
in the discipline of profession education (Tippett, 2010).

"Professional" beliefs about learning and teaching. To what extent do folk beliefs about learning and teaching comport with the beliefs favored in schools, colleges of education, educational research organizations, and other settings in the field of education? Folk beliefs contrast sharply with the beliefs that predominate in the domain of professional education, according to folk belief theory. In most professional settings, beliefs are favored in which (a) knowledge is constructed by individual learners, (b) learning occurs when individuals combine input from the environment with prior knowledge and cognitive skills in an effort to make sense of the world, and (c) teaching is the facilitation of this "constructivist" process, which involves activating prior knowledge, asking questions, and posing problems as well as providing information and supervising activities (e.g., Fosnot \& Jacob, 2010; Brooks \& Brooks, 2001). On this view, activities that involve inquiry, critical thinking, and problem-solving are favored, because these activities encourage students to think for themselves and build cognitive skills. Curriculum-centered activities are not wholly disregarded, typically, but are discounted as more likely to produce disengagement than learning. In general, the beliefs manifest in professional education lean heavily to the student-centered. (This pedagogy is not without its detractors [e.g., Finn \& Kanstoroom, 1999; Hirsch, 1996], but it is widely supported among educators; database searches on “constructivism” and “constructivist” identify over 30,000 publications.)

Folk beliefs and their professional counterparts are very different, but they differ in degree, not in kind. Each viewpoint encompasses both pedagogies, but with discrepant emphases. The contrast is especially salient with regard to curriculum-centered activities, for which professional educators typically have comparatively less use. The difference between folk beliefs and professional ones is smaller for student-centered activities. Hence the theory makes the claim that that measures of support for curriculum-centered pedagogy are likely to produce the largest contrast between the two sets of beliefs.

Folk belief theory is well supported by literature reviewed above. The theory is consistent with research showing that teachers often (but not always) support the student-centered beliefs about learning and teaching favored in the field of education (Chen, Brown, Hattie, \& Millward, 2012; Cheng, Chan, Tang, \& Chan, 2009; Levitt, 2002; Snider \& Roehl, 2007). It is consistent with findings that show non-educators to prefer curriculum-centered pedagogy (Haney, Czerniak, \& Lumpe, 2003; Torff, 2005). The theory comports with findings that show many teachers to be unwavering in their beliefs as they gain education and experience, indicating that beliefs are often resistant to both developmental change (Nettle, 1998; Olafsen, Schraw, \& Vander Velt, 2010; Sosu \& Gray, 2012; Torff, 2005) and explicit attempts to facilitate belief change (Muis \& Duffy, 2013; Polat, 2010; Tanase \& Jian, 2010). And the theory is consistent with research showing curriculum-centered activities to best distinguish individuals who hold folk beliefs from individuals with professional beliefs (Torff, 2005).

But additional research is needed. Folk belief theory emphasizes how individuals with training in education differ from individuals lacking such training, making it crucial that the theory be supported by research examining the beliefs of the untrained (and these beliefs 
compared to those held by professional educators).

This support is scant, but research has clarified that prospective teachersi (at the outset of a teacher education program) are poor representatives for folk beliefs. Torff (2005) reports that prospective teachers favored student-centered pedagogy more than did undergraduate non-educator controls. Self-selection of a teaching career was associated with beliefs supporting student-centered pedagogy, suggesting that people who opt for a career in education are in transition to the professional view and therefore provide an inaccurate window on folk beliefs about learning and teaching.

A better subject pool for studies of folk beliefs would be parents, but there is virtually no research examining parents' beliefs about learning and teaching. The only relevant study published to date surveyed "parents/community members" as well as teachers and school administrators, finding that administrators had more student-centered beliefs relative to parents/community members, but no significant difference between teachers and parents/community members (Haney, Czerniak \& Lumpe, 2003). However, an extremely small sample size (18 parents) made significant differences unlikely and lessened confidence in the generalizability of the results. It remains unclear what parents believe and how these beliefs compare to teachers'.

Remedying this shortfall has much to recommend it. Theoretically speaking, parents provide the unalloyed view of folk beliefs needed for investigations of cultural psychology applied to education. Practically speaking, parents are stakeholders in education whose perspectives should be understood and voices heard. And educators may well benefit from knowing more about the beliefs of parents, with whom they collaborate toward the goal of providing the best education for the child.

\section{Method and Results}

Research questions/hypotheses. To what extent, and in what ways, do differences emerge in beliefs about learning and teaching espoused by parents (untrained in education and likely to hold folk beliefs) and teachers (trained in education and likely to hold professional beliefs)? Specifically, how do these groups differ in support for curriculum-centered activities and student-centered ones? In response to these questions, folk belief theory makes three sets of predictions.

(1) Parents will prefer curriculum-centered to student-centered pedagogy, whereas teachers will express the opposite preferences;

(2) Parents will support curriculum-centered pedagogy markedly more than teachers, whereas teachers will support student-centered pedagogy modestly more than parents (showing that curriculum-centered activities do more to separate the groups than do student-centered activities);

(3) Parents will favor a pedagogical blend long on curriculum-centered activities, whereas teachers will favor a blend emphasizing student-centered ones.

In what follows, I present pilot research to develop the survey instrument and evaluate its 
psychometric characteristics, followed by a study that implements the instrument to assess parents and teachers' beliefs.

\subsection{Study 1: Survey Development}

Research design. The goal of Study 1 was to develop a survey instrument to assess beliefs about learning and teaching. This initiative began with the drafting of 32 items, each a two-sentence description of a commonplace classroom activity in K-12 education. Half of the items were designed to reflect curriculum-centered pedagogy; for example:

A social-studies class is studying the industrial revolution. The teacher provides students with a list of inventions, explains the impact of these inventions during this period, and describes how they continue to influence the modern world.

The other half described a student-centered approach; for example:

A social-studies class is studying how World War I led to World War II. The teacher assigns students to write "letters from the future" to President Wilson arguing why the United States should or should not support the Treaty of Versailles.

The 32 items were balanced to include equal numbers of items in four academic subjects: English, Social Studies, Mathematics, and Science (eight items per subject including four curriculum-centered and four student-centered items). Respondents were asked to rate the educational effectiveness of each item using six-point scales wherein 1=ineffective and $6=$ effective.

Methods. To select the best-performing items and evaluate the psychometric characteristics of the resulting survey instrument, the items were administered to 140 practicing teachers in and near a large city in the northeastern United States. The 99 women and 51 men taught a range of subjects in elementary and secondary education. The participants had a mean age of 42.3 years $(\mathrm{SD}=7.91)$ ranging from 24 to 68 years. In educational attainment, $88 \%$ held a master degree or higher and the remaining $12 \%$ a bachelor's degree. Data were collected at faculty meetings at which teachers had gathered; all teachers asked to participate did so, and none were compensated. Participants were informed that the survey tapped opinions for which there is no correct answer, and that all responses were confidential.

Results. To select the best-performing items, SPSS version 22 was employed in a series of factor-analytic models using the principal components method with varimax rotation. The final model (Figure 1) produced a KMO of .78, explained $62 \%$ of the variance in the responses, and included eight items that loaded onto two factors (interpreted as curriculum-centered and student-centered). The eigenvalues of the two factors were 3.31 and 2.30; the next largest eigenvalue was .76. The eight selected items were balanced to include two in each of the four academic subjects (English, Social Studies, Mathematics, and Science), with one curriculum-centered and one student-centered item per subject. The obtained pattern/structure coefficients (“loadings”) were high: 83, .82, .80, and .76 for items 
interpreted as curriculum-centered; and .81, .76, .75, and .66 for items interpreted as student-centered (all other coefficients were .33 or lower). The two factors produced alphas of .80 and .71 , respectively.

Listed below are descriptions of classroom lessons. Please rate the educational effectiveness of each lesson by circling the appropriate number. Do not rate the importance of the topic; instead, rate how effectively the lesson teaches the topic. Assume that each lesson is well suited to students' age level. This is an opinion survey - there are no correct or incorrect answers. All responses are confidential.

\begin{tabular}{|c|c|c|c|c|c|c|}
\hline 1 & $\begin{array}{l}\text { An English class is studying the sonnet, a form of English } \\
\text { poetry. The teacher explains its history and structure, lists } \\
\text { prominent sonnet writers, and asks individual students to } \\
\text { read aloud several classic sonnets. }\end{array}$ & $\begin{array}{l}1 \\
\text { ineffective }\end{array}$ & 3 & 4 & $\begin{array}{l}5 \\
\text { effective }\end{array}$ & 6 \\
\hline 2 & $\begin{array}{l}\text { A social-studies class is studying the industrial } \\
\text { revolution. The teacher provides students with a list of } \\
\text { inventions, explains the impact of these inventions during } \\
\text { this period, and describes how they continue to influence } \\
\text { the modern world. }\end{array}$ & $\begin{array}{l}1 \\
\text { ineffective }\end{array}$ & 3 & 4 & $\begin{array}{c}5 \\
\text { effective }\end{array}$ & 6 \\
\hline 3 & $\begin{array}{l}\text { A mathematics class is studying single-variable algebra. } \\
\text { The teacher asks students to come up with word problems } \\
\text { that are solved with single-variable algebra, solve them, } \\
\text { and present their work to the class. }\end{array}$ & $\begin{array}{l}1 \\
\text { ineffective }\end{array}$ & 3 & 4 & $\begin{array}{l}5 \\
\text { effective }\end{array}$ & 6 \\
\hline 4 & $\begin{array}{l}\text { A science class is studying weather. The teacher gives an } \\
\text { assignment in which students match key terms (e.g., } \\
\text { barometric pressure) with their definitions. }\end{array}$ & $\begin{array}{l}1 \\
\text { ineffective }\end{array}$ & 3 & 4 & $\begin{array}{c}5 \\
\text { effective }\end{array}$ & 6 \\
\hline 5 & $\begin{array}{l}\text { A social-studies class is studying how World War I led to } \\
\text { World War II. The teacher assigns students to write } \\
\text { "letters from the future" to President Wilson arguing why } \\
\text { the United States should or should not support the Treaty } \\
\text { of Versailles. }\end{array}$ & $\begin{array}{l}1 \\
\text { ineffective }\end{array}$ & 3 & 4 & $\begin{array}{c}5 \\
\text { effective }\end{array}$ & 6 \\
\hline 6 & $\begin{array}{l}\text { A science class is studying the sun. The teacher asks } \\
\text { students to write down several ways in which the sun } \\
\text { influences everyday life and then to predict what would } \\
\text { happen if the sun stopped shining. }\end{array}$ & $\begin{array}{l}1 \\
\text { ineffective }\end{array}$ & 3 & 4 & $\begin{array}{c}5 \\
\text { effective }\end{array}$ & 6 \\
\hline 7 & $\begin{array}{l}\text { A mathematics class is studying the order of operations. } \\
\text { The teacher describes the order of operations for the } \\
\text { students while doing sample problems on the blackboard, } \\
\text { and then asks students to complete similar problems in } \\
\text { their textbooks. }\end{array}$ & $\begin{array}{l}1 \\
\text { ineffective }\end{array}$ & 3 & 4 & $\begin{array}{c}5 \\
\text { effective }\end{array}$ & 6 \\
\hline 8 & $\begin{array}{l}\text { An English class is studying Jack London's short story To } \\
\text { Build a Fire. The teacher asks students to read all but the } \\
\text { last section and then write their own versions of the final } \\
\text { section. }\end{array}$ & $\begin{array}{l}1 \\
\text { ineffective }\end{array}$ & 3 & 4 & $\begin{array}{c}5 \\
\text { effective }\end{array}$ & 6 \\
\hline
\end{tabular}

Figure 1. Survey Instrument 
As shown in Table 1, participants in the two groups were similar in age. The sample in both groups contained more women than men by a substantial margin, which in the teacher group is unsurprising because the workforce of teachers in the United States remains predominantly female, especially at the elementary level. As for ethnicity, the parent group had greater minority representation, with 51 nonwhites in the parent group (24\%) but only 20 (10\%) in the teacher group; this discrepancy reflects nationwide trends with underrepresentation of minorities in the teaching workforce (National Research Council, 2011). The teacher group had somewhat higher educational attainment, likely because teacher certification regulations in the state in which the study was conducted require teachers to attain a master's degree within five years of completion of the bachelor's.

\section{Procedure}

Data were collected by 19 research assistants in a large northeastern city and surrounding suburbs. To collect data from teachers, research assistants attended faculty meetings at public schools, where they asked teachers to complete the survey at the beginning of the meeting. All teachers asked to complete a survey did so, allowing researchers to avoid response-rate problems that sometimes occur with online and mailed surveys. To collect data from parents, research assistants attended events at which parents congregated; these events include back-to-school nights, athletic events, music and dance concerts, art shows, science fairs, and other events held at public schools. All participants were told that the opinion survey had no correct answers and that responses were confidential. None were compensated. Survey data were entered into SPSS version 22 for statistical analysis.

Table 2. Means and Standard Deviations for Dependent Variables, By Group

\begin{tabular}{lcccc}
\hline \multirow{2}{*}{ Variable } & \multicolumn{2}{c}{ Parents } & \multicolumn{2}{c}{ Teachers } \\
\cline { 2 - 5 } & Mean & SD & Mean & SD \\
\hline Curriculum-centered & & & & \\
All subjects & 4.46 & .80 & 3.24 & .85 \\
English & 4.47 & 1.18 & 3.17 & 1.29 \\
Social Studies & 4.79 & 1.10 & 3.37 & 1.35 \\
Math & 4.42 & 1.26 & 3.82 & 1.20 \\
Science & 4.17 & 1.38 & 2.61 & 1.12 \\
\hline Student-centered & & & & \\
All subjects & 4.25 & .80 & 4.80 & .80 \\
English & 4.28 & 1.22 & 4.38 & 1.46 \\
Social Studies & 3.89 & 1.33 & 5.09 & .94 \\
Math & 4.25 & 1.43 & 4.89 & 1.32 \\
Science & 4.56 & 1.20 & 4.82 & 1.00 \\
\hline SC-CC Mean Difference & & & & \\
All subjects & -.22 & .78 & 1.55 & 1.06 \\
English & -.18 & .84 & 1.20 & 1.67 \\
Social Studies & -.90 & .72 & 1.72 & .82 \\
Math & -.17 & 1.37 & 1.08 & .84 \\
Science & .39 & 1.20 & 2.20 & 1.32 \\
\hline
\end{tabular}

Notes. $\mathrm{SC}=$ student-centered. $\quad \mathrm{CC}=$ curriculum centered. 
$\underline{\text { Results }}$

Descriptive statistics for the four control variables (age, gender, ethnicity, and educational attainment) are set out in Table 1 . Table 2 presents means and standard deviations for the eight dependent variables included in the study. All statistical procedures were conducted using SPSS version 22.

Replication of the psychometric properties of the instrument. A confirmatory factor analysis was performed on the eight items using the principal components method with varimax rotation. The KMO for the model was .69. The eight-item, two-factor model explained 61\% of the variance in the responses. The eigenvalues of the two factors were 2.60 and 2.28; the next largest eigenvalue was .93. The obtained pattern/structure coefficients were .83, .83, .77, and .76 for items interpreted as curriculum-centered and .80, .77, .77, and .67 for items interpreted as student-centered; other loadings were .42 or lower. The two factors produced alphas of .63 and .62, respectively. The model's favorable psychometric properties allowed it to be deemed appropriate for further analyses of the dataset.

Within-subjects analyses. To examine respondents' beliefs about curriculum-centered and student-centered pedagogies in within-subjects analyses, two t-tests were conducted taking the mean of the four curriculum-centered items as the first factor and the mean of the four student-centered items as a second factor. Both had distributions of satisfactory normality in Shapiro-Wilk testing. Parents showed a strong preference curriculum-centered over student-centered pedagogy $(t=3.80, \mathrm{p}<.0001)$. Teachers evinced an equally strong opposite preference, favoring student-centered over curriculum-centered pedagogy $(t=-22.08, \mathrm{p}$ $<.0001)$.

Between-subjects analyses. To compare the two groups and explore effects associated with the control variables, a MANCOVA procedure was performed. The dependent variables were the mean of the combined curriculum-centered items and the mean of the combined student-centered items. The five independent variables were group, age, gender, ethnicity, and educational attainment. Interactions among the control variables were insignificant. Evaluation of assumptions of normality of sampling distributions, linearity, and homogeneity of variance was satisfactory. No univariate within-cell outliers were obtained at alpha $=.001$. The MANCOVA produced significant differences for the combined dependent variables, $F(2$, $271)=8013.43, \mathrm{p}<.0001$ (partial eta-squared $=.98)$.

For curriculum-centered items, the difference between groups was statistically significant, $F(1,272)=99.36, \mathrm{p}<.0001$ (partial eta-squared $=.27$ ), such that parents were higher than teachers. Significant influence on ratings of curriculum-centered items was also found for three control variables: age, $F(36,272)=17.02, \mathrm{p}<.0001$ (partial eta-squared $=.69$ ); ethnicity, $F(3,272)=99.36, \mathrm{p}<.0001$ (partial eta-squared $=.32$ ); and educational attainment $F(5,272)=10.66, \mathrm{p}<.0001$ (partial eta-squared $=.16$ ). Taken together these findings indicate that parents were more supportive of curriculum-centered pedagogy than were teachers, controlling for age, ethnicity, and educational attainment.

The difference between groups was statistically significant as well for studlent-centered items, 
although the effect was smaller, and in this case the teachers produced the higher ratings: $F(1$, $272)=14.56, \mathrm{p}<.0001$ (partial eta-squared $=.05$ ). Four control variables produced significant influence on ratings of student-centered items: age, $F(36,272)=12.52$, $\mathrm{p}<.0001$ (partial eta-squared = .62); gender, $F(1,272)=19.03, \mathrm{p}<.0001$ (partial eta-squared $=.07$ ); ethnicity, $F(3,272)=7.61, \mathrm{p}<.0001$ (partial eta-squared $=.08$ ); and educational attainment $F(5,272)=2.41, \mathrm{p}<.05$ (partial eta-squared $=.04$ ). These findings show that teachers evinced stronger support for student-centered pedagogy than did parents, controlling for age, gender, ethnicity, and educational attainment.

To further explore these group differences in beliefs about learning and teaching, an ANCOVA procedure was performed on the difference between the means of the curriculumand student-centered items. Calculating this mean differential generates a "pedagogical preference" value (ranging from -6 to 6), such that a negative number reveals a preference for curriculum-centered pedagogy and a positive number a preference for student-centered pedagogy. The pedagogical preference value enables univariate analyses of the extent to which the independent variables (including group) are associated with pedagogical preferences. In the ANCOVA, the pedagogical preference value was the dependent variable, and the independent variables were group, age, gender, ethnicity, and educational attainment. Evaluation of assumptions inherent in general linear models produced satisfactory results. The ANCOVA yielded a significant difference for the dependent variable, $F(136,272)=$ 19.24, $\mathrm{p}<.0001$ (partial eta-squared $=.91$ ).

A statistically significant group difference was found, $F(1,272)=223.4, p<.0001$ (partial eta-squared $=.31$ ), such that teachers were higher than parents. Significant differences were also obtained for four control variables: age, $F(36,272)=10.02, \mathrm{p}<.0001$ (partial eta-squared $=.57$ ); gender, $F(1,272)=6.43, \mathrm{p}<.05$ (partial eta-squared $=.02)$; ethnicity, $F(3$, $272)=9.36, \mathrm{p}<.0001$ (partial eta-squared $=.09$ ); and educational attainment $F(5,272)=$ $5.01, \mathrm{p}<.05$ (partial eta-squared $=.08$ ). Controlling for age, gender, ethnicity, and educational attainment, teachers produced a higher student-centered pedagogical preference value than did parents, indicating a more student-centered approach to learning and teaching.

\section{Discussion}

This study unearthed multiple indications that parents and teachers think very differently about what learning is and how teaching should proceed. These differences can be summarized as follows:

(1) Parents preferred curriculum-centered activities over student-centered ones; but teachers favored the opposite, preferring student-centered over curriculum-centered activities by a considerable margin.

(2) Parents supported curriculum-centered activities much more than teachers did; teachers again favored the opposite, supporting student-centered activities more than parents did. The effect was much stronger for curriculum-centered activities, the variable with the largest group differences. 
(3) Parents preferred a pedagogical blend of curriculum-centered and student-centered favoring the former, while teachers preferred a blend emphasizing student-centered activities.

Theoretical implications. The findings are congruent with folk belief theory, which predicts that untrained individuals adhere to culturally-provided folk beliefs that prize curriculum-centered pedagogy while teachers emphasize student-centered pedagogy as a consequence of their immersion in the education profession (Torff, 2011, 2014). More generally, the results are consistent with the basic tenets of cultural psychology, which hold that cultural factors such as "folk psychology" organize the way individuals think about the world (Bruner, 1990; Geary, 2005; Horgan \& Woodward, 1999; Hutto, 2008).

The findings are also consistent with research showing that prospective teachers begin their careers supporting curriculum-centered pedagogy but later come to rethink these views as they gain education and experience (Tippett, 2010; Torff, 2005). And the results are consistent with the claim that the groups differ most with respect to curriculum-centered pedagogy (Torff, 2011, 2014).

As predicted, the groups differ mainly in degree, not in kind. Parents supported both pedagogies, but preferred curriculum-centered by a wide margin. Teachers also supported both pedagogies but favored a highly limited role for the curriculum-centered one. In general, the results underscore the utility of studies that examine in detail what untrained individuals believe about education, how these beliefs compare to the ones manifest in professional education, and how beliefs change (and resist change) when prospective teachers encounter professional education.

Educational implications. Documenting marked differences between parents and teachers, the study underscores that these stakeholders in education communicate across a substantial divide. As such, interaction between parents and teachers is not a straightforward process wherein two parties communicate in an unproblematic manner while working toward a common goal. In this case, the parties agree on the ends (the education of the student) but not the means (the appropriate pedagogy for educating the student). Viewed as such, parent/teacher interactions become considerably more complicated and fraught with the possibility of conflict.

Awareness of this divide on the part of parents and teachers changes the interaction between the two. The element of negotiation has been added to the conversation - as would happen whenever interlocutors disagree but must continue to collaborate. In essence, the interpersonal dynamics of disagreeing become operative.

Hence, the literatures in such topics as conflict resolution and conflict management become relevant (e.g., Forsyth, 2009). But this literature is remote from education in the main, devoted more often to business negotiations and personal relationships. Unsurprisingly it is rarely included in teacher-education programs. A body of literature for teachers on the topic of working with parents has been published (e.g., Lawrence-Lightfoot, 2004; Olsen \& Fuller, 2011), but even this literature is seldom assigned reading in preservice teacher education. 
Techniques for working with parents are discussed on occasion in inservice education programs (i.e., professional development initiatives), but topics as such are often squeezed out in these times of educational reform, when adjusting to reform mandates has become a considerable undertaking for educators.

This study's findings suggest that teachers might well benefit from training in interactions with parents, training focused on dealing with disagreements concerning the relative merits of curriculum- and student-centered pedagogical approaches. But at present this training is rare at both the preservice and inservice levels.

From an educational policy standpoint, the divide between parents and teachers has different implications depending on which type of pedagogy is preferred. For advocates for curriculum-centered pedagogy (e.g., Finn \& Kanstoroom, 1999; Hirsch, 1987, 1996), the results demonstrate that the education establishment is insufficiently responsive to the parents whose children provide the reason for schools to exist and whose taxes keep the schools operating. On this view, teachers should recognize that the pedagogy they espouse is not favored in the community and might well be revised in a timely manner. For advocates of curriculum-centered pedagogy, this study's results provide an indication that parents need to be more vocal in demanding that schools adopt the pedagogy valued by the community.

These conclusions are explicitly opposed by advocates for student-centered pedagogy (e.g., Alexander \& Murphy, 2000; Richardson \& Placier, 2002). From this viewpoint, the study's results demonstrate a need to ensure that teacher-education programs work to foster appropriate belief change in their charges, since the initial state of beliefs with which prospective teachers begin is often impoverished. The findings also suggest a need for educators at all levels to redouble their efforts to educate the public about effective teaching, much as physicians attempt to educate the public concerning healthy nutrition.

Limitations and future research. The research requires replication, especially using larger sample sizes that increase confidence in the generalizability of the results. It would seem fruitful that the survey be administered to administrators and expert teachers, to determine the extent of variance in beliefs within the population of educators in our culture. Research is needed as well in different geographical regions, given that this study's participants were all residents in and around the same large city in the northeastern United States. Because this study grows out of a theory assuming that culture plays a considerable role in the formation of the beliefs held by individuals, it follows that the survey should be administered to parents and educators across a wide area, including non-Western settings. Comparison of Western and non-Western beliefs, particularly in Asia, would be especially illuminating, given the suggestion that many Asian societies value a curriculum-centered approach both in folk beliefs and in professional education (e.g., Sang et al., 2012; Sy \& Schulenberg, 2005).

Returning to the parent-teacher conversation in this article's opening paragraph, it's clear that the incongruity experienced by the two parties was no isolated incident. They brought conflicting pedagogical beliefs to the conversation, perhaps because the parent adhered to folk beliefs about education that are prevalent in our culture, while the teacher supported a different set of beliefs that are favored in the field of professional education. In such 
interactions, understanding each other's viewpoint and striving to work together is the formula best serves the interests of the child.

\section{References}

Alexander, P., \& Murphy, P. (2000). The research base for APA's leaner-centered psychological principles. In N. Lambert \& B. McCombs (Eds.), How students learn (pp. 25-60). Washington, D.D.: American Psychological Association.

Bandura, A. (1997). Self-efficacy: The exercise of control. New York: W.H. Freeman.

Brooks, M. G., \& Brooks, J. (2001). In search of understanding the case for constructivist classrooms: with a new introduction by the authors. United States of America: Merrill\Prentice Hall.

Bruner, J. (1990). Culture and human development: a new look. Human Development (0018716X), 33344-355. http://dx.doi.org/10.1159/000276535

Buchanan, C. M., Eccles, J. S., Flanagan, C., Midgley, C., Feldlaufer, H., \& Harold, R. D. (1990). Parents' and teachers' beliefs about adolescents: Effects of sex and experience. Journal of Youth and Adolescence, 19(4), 363-394. http://dx.doi.org/10.1007/BF01537078

Buehl, M. M., \& Fives, H. (2009). Exploring teachers' beliefs about teaching knowledge: Where does it come from? Does it change? .Journal of Experimental Education, 77(4), 367-407. http://dx.doi.org/10.3200/JEXE.77.4.367-408

Cady, J., \& Rearden, K. (2007). Pre-service teachers' beliefs about knowledge, mathematics, and science. School Science \& Mathematics, 107(6), 237-245. http://dx.doi.org/10.1111/j.1949-8594.2007.tb18285.x

Chen, J., Brown, G. L., Hattie, J. C., \& Millward, P. (2012). Teachers' conceptions of excellent teaching and its relationships to self-reported teaching practices. Teaching \& Teacher Education, 28(7), 936-947. http://dx.doi.org/10.1016/j.tate.2012.04.006

Cheng, M. H., Chan, K., Tang, S. F., \& Cheng, A. N. (2009). Pre-service teacher education students' epistemological beliefs and their conceptions of teaching. Teaching and Teacher Education: An International Journal of Research and Studies, 25(2), 319-327. http://dx.doi.org/10.1016/j.tate.2008.09.018

Cole, M. (1996). Cultural psychology: A once and future discipline. Cambridge, MA US: Harvard University Press.

DiSessa, A. A. (1996). What do 'just plain folk' know about physics?. In D. R. Olson, N. Torrance (Eds.), The handbook of education and human development: New models of learning, teaching and schooling (pp. 709-730). Malden: Blackwell Publishing.

Fang, Z. (1996). A review of research on teacher beliefs and practices. Educational Research, 38(1), 47-65. http://dx.doi.org/10.1080/0013188960380104

Finn, C., \& Kanstoroom, M (1999). Better teacher, better schools. Washington: Fordham 
Foundation.

Flowerday, T., \& Schraw, G. (2000). Teacher beliefs about instructional choice: A phenomenological study. Journal of Educational Psychology, 92(4), 634-645. http://dx.doi.org/10.1037/0022-0663.92.4.634

Forsyth, D. R. (2009). Group dynamics (5th ed.). Pacific Grove, CA: Brooks/Cole. http://dx.doi.org/10.4135/9781412958479.n248

Fosnot, C., Jacob, B., \& National Council of Teachers of, M. (2010). Young mathematicians at work: Constructing algebra. National Council of Teachers of Mathematics.

Franco, G. M., Muis, K. R., Kendeou, P., Ranellucci, J., Sampasivam, L., \& Wang, X. (2012). Examining the influences of epistemic beliefs and knowledge representations on cognitive processing and conceptual change when learning physics. Learning and Instruction, 22(1), 62-77. http://dx.doi.org/10.1016/j.learninstruc.2011.06.003

Gardner, H. (1991). The unschooled mind: How children think \& how schools should teach.

Geary, D. C. (2005). Role of cognitive theory in the study of learning disability in mathematics. Journal of Learning Disabilities, 38(4), 305-307. http://dx.doi.org/10.1177/00222194050380040401

Green, H. J., \& Hood, M. (2013). Significance of epistemological beliefs for teaching and learning psychology: A review. Psychology Learning \& Teaching, 12(2), 168-178. http://dx.doi.org/10.2304/plat.2013.12.2.168

Hancock, E. S., \& Gallard, A. J. (2004). Preservice science teachers' beliefs about teaching and learning: The influence of K-12 field experiences. Journal of Science Teacher Education, 15(4), 281-291. http://dx.doi.org/10.1023/B:JSTE.0000048331.17407.f5

Haney, J. J., Czerniak, C. M., \& Lumpe, A. T. (2003). Constructivist beliefs about the science classroom learning environment: Perspectives from teachers, administrators, parents, community members, and students. School Science \& Mathematics, 103(8), 366-377. http://dx.doi.org/10.1111/j.1949-8594.2003.tb18122.x

Hirsch, E. D. (1987). Cultural literacy: What every american needs to know. New York: Vintage Books.

Hirsch, E. D. (1996). The schools we need: And why we don't have them. New York: Anchor Books.

Hofer, B. K. (2004). Exploring the dimensions of personal epistemology in differing classroom contexts: Student interpretations during the first year of college. Contemporary Educational Psychology, 29, 129-163. http://dx.doi.org/10.1016/j.cedpsych.2004.01.002

Hofer, B. K. (2004). Introduction: Paradigmatic approaches to personal epistemology. Educational Psychologist, 39(1), 1-3. http://dx.doi.org/10.1207/s15326985iep3901_1

Horgan, T., \& Woodward, J. (1993). Folk psychology is here to stay. In S. M. Christensen \& 
D. R. Turner (Eds.), Folk psychology and the philosophy of mind (pp. 144-166). Hillsdale, NJ England: Lawrence Erlbaum Associates, Inc.

Hutto, D. D. (2008). Folk psychological narratives: The sociocultural basis of understanding reasons. Cambridge, MA US: MIT Press.

Kuhn, D., \& Weinstock, M. (2002). What is epistemological thinking and why does it matter?. In B. K. Hofer \& P. R. Pintrich (Eds.), Personal epistemology: The psychology of beliefs about knowledge and knowing (pp. 121-144). Mahwah, NJ US: Lawrence Erlbaum Associates Publishers.

Lawrence-Lightfoot, S. (2004). The essential conversation: what parents and teachers learn from each other. New York, NY: Ballantine Books.

Levitt, K. E. (2002). An analysis of elementary teachers' beliefs regarding the teaching and learning of science. Science Education, 86(1), 1. http://dx.doi.org/10.1002/sce.1042

Maggioni, L., \& Parkinson, M. M. (2008). The role of teacher epistemic cognition, epistemic beliefs, and calibration in instruction. Educational Psychology Review, 20(4), 445-461. http://dx.doi.org/10.1007/s10648-008-9081-8

Muis, K., \& Duffy, M. (2013). Epistemic climate and epistemic change: Instruction designed to change students' beliefs and learning strategies and improve achievement. Journal of Educational Psychology, 105(1), 213-225. http://dx.doi.org/10.1037/a0029690

National Research Council. (2011). Expanding underrepresented minority participation: America's science and technology talent at the crossroads. Washington, DC: The National Academies Press.

Nettle, E. B. (1998). Stability and change in the beliefs of student teachers during practice

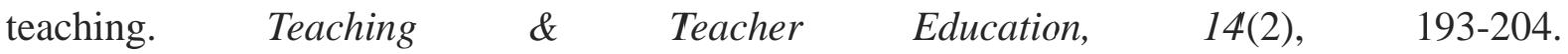
http://dx.doi.org/10.1016/S0742-051X(97)00031-0

Nissani, M., \& Hoefler-Nissani, D. (1992). Experimental studies of belief dependence of observations and of resistance to conceptual change. Cognition \& Instruction, 9(2), 97-111. http://dx.doi.org/10.1207/s1532690xci0902_1

Olafson, L., \& Schraw, G. (2002). Some final thoughts on the epistemological melting pot. Issues in Education, 8(2), 233.

Olafson, L., \& Schraw, G. (2006). Teachers' beliefs and practices within and across domains. International Journal of Educational Research, 45(1-2), 71-84. http://dx.doi.org/10.1016/j.ijer.2006.08.005

Olafson, L., Schraw, G., \& Vander Veldt, M. (2010). Consistency and development of teachers' epistemological and ontological world views. Learning Environments Research, 13(3), 243-266. http://dx.doi.org/10.1007/s10984-010-9078-3

Olsen, G. W., \& Fuller, M. (2011). Home-school relations: Teachers and parents working together(4th ed.). Upper Saddle River, NJ: Pearson. 
Perry, D. K., \& Minnesota Univ. (1970). The minnesota college statewide testing program--1970: Its current values and future development.

Pintrich, P. R. (2002). The role of metacognitive knowledge in learning, teaching, and assessing. Theory Into Practice, 41(4), 219-225. http://dx.doi.org/10.1207/s15430421 tip4104_3

Polat, N. (2010). Pedagogical treatment and change in preservice teacher beliefs: An experimental study. International Journal of Educational Research, 49(6), 195-209. http://dx.doi.org/10.1016/j.ijer.2011.02.003

Richardson, Virginia. (1996). The role of attitudes and beliefs in learning to teach. In John Sikula (Ed.), Handbook of research on teacher education (2nd ed., pp. 102-119). New York: Macmillan.

Richardson, V. \& Placier, P. (2002). Teacher change. In V. Richardson (Ed.), Handbook of research on teaching (4th ed., pp. 905-947). Washington, DC: American Educational Research Association.

Sampson, V., Enderle, P., \& Grooms, J. (2013). The development and initial validation of the beliefs about reformed science teaching and learning (BARSTL) questionnaire: An instrument that measures the beliefs of elementary school science teachers. School Science and Mathematics, 113(1), 3-15. http://dx.doi.org/10.1111/j.1949-8594.2013.00175.x

Sang, G., Valke, M., Tondeur, J., Zhu, C., \& Von Braak. (2012), Exploring the educational beliefs of primary education student teachers in the Chinese context. Asia Pacific Educational Review, 13, 417-425. http://dx.doi.org/10.1007/s12564-012-9206-0

Schommer, M. (1994). Synthesizing epistemological belief research: Tentative understandings and provocative confusions. Educational Psychology Review, 6(4), 293. http://dx.doi.org/10.1007/BF02213418

Sinatra, G., \& Kardash, C. (2004). Teacher candidates’ epistemological beliefs, dispositions, and views on teaching as persuasion. Contemporary Educational Psychology, 29, 483-498. http://dx.doi.org/10.1016/j.cedpsych.2004.03.001

Snider, V. E., \& Roehl, R. (2007). Teachers' beliefs about pedagogy and related issues. Psychology in the Schools, 44(8), 873-886. http://dx.doi.org/10.1002/pits.20272

Sosu, E. M., \& Gray, D. S. (2012). Investigating change in epistemic beliefs: An evaluation of the impact of student teachers' beliefs on instructional preference and teaching competence. International Journal of Educational Research, 5380-92. http://dx.doi.org/10.1016/j.ijer.2012.02.002

Shweder, R. (1991). Thinking through cultures. Cambridge, MA: Harvard University Press.

Sy, S. R., \& Schulenberg, J. E. (2005). Parent beliefs and children's achievement trajectories during the transition to school in Asian American and European American families. International Journal of Behavioral Development, 29(6), 505-515. 
http://dx.doi.org/10.1080/01650250500147329

Tanase, M., \& Wang, J. (2010). Initial epistemological beliefs transformation in one teacher education classroom: Case study of four preservice teachers. Teaching \& Teacher Education, 26(6), 1238-1248. http://dx.doi.org/10.1016/j.tate.2010.02.009

Tanriverdi, B. (2012). Pre-Service teachers' epistemological beliefs and approaches to learning. Procedia - Social and Behavioral Sciences, 46, 2635-2642. http://dx.doi.org/10.1016/j.sbspro.2012.05.538

Tippett, C. D. (2010). Refutation text in science education: A review of two decades of research. International Journal of Science and Mathematics Education, 8(6), 951-970. http://dx.doi.org/10.1007/s10763-010-9203-x

Torff, B. (2005). Developmental changes in teachers' beliefs about critical-thinking activities. $\begin{array}{llll}\text { Journal of } & \text { Educational } & \text { Psychology, } & \text { 97(1), }\end{array}$ http://dx.doi.org/10.1037/0022-0663.97.1.13

Torff, B. (2006). Expert teachers' beliefs about use of critical-thinking activities with high and low-advantage learners. Teacher Education Quarterly, 33(2), 37-52.

Torff, B. (2013). Folk belief theory: Accounting for the persistence of theachievement gap. In B. J. Irby, G. Brown, R. Lara-Alecio, \& S. Jackson (Eds.) and P. Jenlink (Sect. Ed.), The Handbook of Educational Theories (pp. 259-270). Charlotte, NC: Information Age Publishing, Inc.

Torff, B. (in press). Folk belief theory, the rigor gap, the achievement gap. The Educational Forum.

Varrella, G. F., \& Burry-Stock, J. (1996). Beliefs of constructivist teachers using a novice through expert rubric.

Warburton, E., \& Torff, B. (2005). The effect of perceived learner advantages on teachers' beliefs about critical-thinking activities. Journal of Teacher Education, 56(1), 24-33. http://dx.doi.org/10.1177/0022487104272056

Weinstein, C. (1998). "I want to be nice, but I have to be mean": exploring prospective teachers' conceptions of caring and order. Teaching \& Teacher Education, 14(2), 153-163. http://dx.doi.org/10.1016/S0742-051X(97)00034-6

Zhou, J. (2009). Teaching evaluation: A critical measure for improving the quality of $\begin{array}{lllll}\text { education. Chinese Education } \quad \& \quad \text { Society, } & 42(2), & \text { 7-19. }\end{array}$ http://dx.doi.org/10.2753/CED1061-1932420201

\section{Copyright Disclaimer}

Copyright reserved by the authors.

This article is an open-access article distributed under the terms and conditions of the Creative Commons Attribution license (http://creativecommons.org/licenses/by/3.0/). 